Báez, Algacel Luis. El catastrófico arte de contar historias sobre el dios Vulcano. GeoGraphos [En línea]. Alicante: Grupo Interdisciplinario de Estudios Críticos y de América Latina (GIECRYAL) de la Universidad de Alicante, 2 de septiembre de 2020, vol. 11, no 130 p. 216-244 [ISSN: 2173-1276] [DL: A 371-2013] [DOI: 10.14198/GEOGRA2020.11.130].

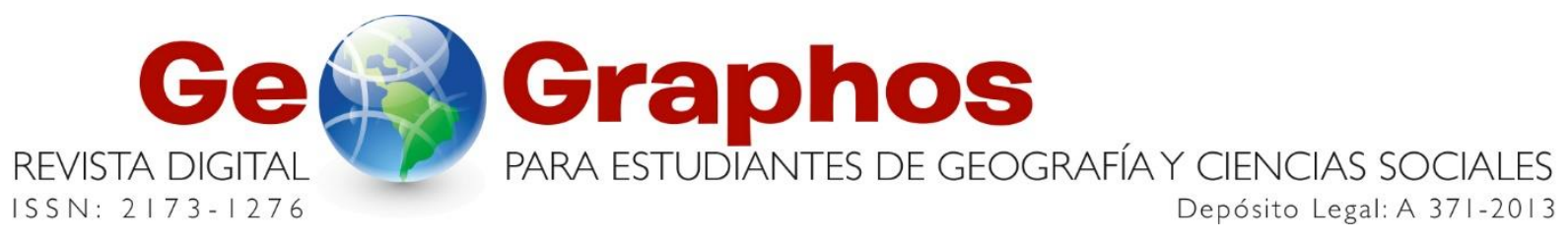

<http://web.ua.es/revista-geographos-giecryal $>$

Vol. 11. No 130

Año 2020

\title{
EL CATASTRÓFICO ARTE DE CONTAR HISTORIAS SOBRE EL DIOS VULCANO
}

\author{
Algacel Luis Báez \\ Licenciado en Geografía e Historia \\ Máster de Formación del Profesorado de Educación Secundaria Obligatoria, \\ Bachillerato, Formación Profesional y Enseñanza de Idiomas. Humanidades. \\ Universidad de La Laguna (San Cristóbal de La Laguna, Santa Cruz de Tenerife, \\ Islas Canarias, España). \\ Correo electrónico: geovolcanica@gmail.com
}

Recibido: 16 de junio de 2020. Aceptado: 02 de septiembre de 2020 


\title{
RESUMEN
}

Los volcanes constituyen uno de los fenómenos más conocidos y, al mismo tiempo, impredecibles de la naturaleza. Asombrosos, admirados y mitificados por el ser humano, modelan parte de la sociedad, dando forma a nuestra historia. Su poder ha generado grandes transformaciones en el paisaje y el clima, efectuando, a la par, influyentes cambios en acontecimientos de gran relevancia histórica, económica y artística. Sin embargo, pese a su constatada influencia, los volcanes y su actividad eruptiva no destacan como uno de los contenidos fundamentales del mundo académico. Por ello, en esta obra se propone un proceso de aprendizaje mediante una estrategia educativa que gire en torno a una serie de eventos históricos, surgidos ante algunos de los episodios volcánicos más destacados de la Historia de la humanidad.

Palabras clave: Geografía e Historia, Aprendizaje Basado en Proyectos (ABP), Aprendizaje Basado en Cuentos Infográficos (ABCI), educación; volcanes.

\section{THE CATASTROPHIC ART OF TELLING STORIES ABOUT THE VULCAN GOD}

\begin{abstract}
The volcanoes are one of the bases of the best known and, at the same time, unpredictable processes in nature. Amazing, admired and mythologized by the human being, they shape part of society, shaping our history from the beginning of time. Its power has carried out great transformations in the landscape and the climate, generating, at the same time, influential changes in some events of great historical, economic and artistic relevance. However, despite their influence, volcanoes and their eruptive activity do not stand out as one of the fundamental topics in the academic world. Therefore, a learning process is proposed through an educational strategy that revolves around these historical events, arising from some of the most outstanding volcanic episodes in the history of humanity.
\end{abstract}

Key words: Geography \& History, Project-based Learning (PBL), Infographic and Story-based Learning (ISBL), education; volcanoes.

\section{A ARTE CATASTRÓFICA DE CONTAR HISTÓRIAS SOBRE O DEUS VULCANO}

\section{RESUMO}

Os vulcões são uma das bases dos processos mais conhecidos e, ao mesmo tempo, imprevisíveis na natureza. Surpreendentes, admirados e mitologizados pelo ser humano, eles formam parte da sociedade, moldando nossa história desde o início dos tempos. Seu poder realizou grandes transformações na paisagem e no clima, gerando, ao mesmo tempo, mudanças influentes em alguns eventos de grande relevância histórica, econômica e artística. No entanto, apesar de sua influência, os vulcões e sua atividade eruptiva não se destacam como um dos tópicos fundamentais no mundo acadêmico. Por esse motivo, um processo de aprendizado é proposto por meio de 
uma estratégia educacional que gira em torno desses eventos históricos, decorrentes de alguns dos episódios vulcânicos mais marcantes da história da humanidade.

Palavras chave: Geografia e História, Aprendizagem Baseada em Projetos (ABP), Infográfico e Aprendizagem Baseada em História (IABH), educação; vulcões.

\section{INTRODUCCIÓN}

Los volcanes son uno de los procesos más comunes de La Tierra, llegando a promediarse unos cincuenta eventos eruptivos al año, agrupados "en el periodo histórico mejor conocido en todo el mundo, los últimos 5 siglos (...), y eso que solo se pueden reconocer aquellas que ocurren en tierra, pasando casi desapercibidas las que deben tener lugar en los fondos marinos" (Pérez, 2015, p. 3).

Pero, ¿qué es en realidad un volcán? Realizar una definición precisa de un volcán es un asunto complejo, arduo y espinoso, pero no por ello imposible. Lo primero que hay que tener en cuenta es la diferencia entre la forma del volcán y los procesos que generan esa morfología (es decir, las características diferenciadoras del tipo de actividad volcánica). Teniendo en cuenta esto, podemos concluir que no es lo mismo su morfología, que la actividad volcánica que la genera. Así, según Pujadas et al. (1999), un volcán puede ser definido como la certeza geológica de la llegada de productos magmáticos a un lugar de la superficie terrestre, referida ésta a las concentraciones de magma, a las estructuras y a los materiales surgidos tras el episodio eruptivo. Mientras que su actividad volcánica es el "resultado final de un conjunto de procesos que van desde la génesis del magma hasta la erupción, pasando por el ascenso y almacenamiento de éste" (Pujadas et al., 1999, p. 201).

Si bien la sociedad relaciona a los volcanes con un proceso virulento, maligno y venenoso de la naturaleza, éstos son uno de los más importantes mecanismos creadores de vida, marcando pautas positivas al modificar y adaptar los terrenos donde se asientan las civilizaciones humanas. Así, los espacios volcánicos suponen áreas de gran fertilidad para la agricultura o lugares adecuados para el almacenamiento del agua en acuíferos. Debido a estas condiciones favorables, la población ha vivido en torno a las grandes áreas volcánicas, generando varios episodios catastróficos o destructivos que han marcado el devenir de las sociedades en el pasado. Sin embargo, su influencia no se ha limitado a los entornos volcánicos más inmediatos, constituyendo a menudo un fenómeno a escala global. Al mismo tiempo, aunque los volcanes constituyen uno de los espectáculos más fascinantes de la naturaleza, su influencia va más allá de su mera actividad eruptiva, siendo la posible causa de alguno de los acontecimientos históricos y geográficos más asombrosos, debido a que "es uno de los pocos fenómenos geológicos que se manifiesta a escala temporal humana" (Pérez, 2015, p. 3).

Desde los más bellos atardeceres hasta la oscuridad tenebrosa de una tarde de verano, el poder de los volcanes no deja de sorprendernos. Por ello, una de las manifestaciones naturales que más se ha visto influida por los sucesos de origen volcánico ha sido el clima. En este sentido, si un volcán cambia el clima, aunque sea 
temporalmente, muchas de las actividades fundamentales del ser humano se ven alteradas, provocando desde la pérdida de productividad en las cosechas y el ganado (desembocando en hambrunas, epidemias y revueltas), hasta profundos cambios paisajísticos y artísticos. Por ello "no es de extrañar que esté presente en los libros de texto de casi todas las etapas educativas, desde la Primaria hasta la Universitaria, aún más patente en la Comunidad Autónoma de Canarias" (Pérez, 2015, p. 3), como espacio volcánico por excelencia dentro del territorio nacional español. Lo que nos ha llevado a plantearnos cuál ha sido su papel educativo, el peso que tiene dentro del currículum y cómo mejorar su inclusión y trascendencia en el proceso de enseñanza y aprendizaje, principalmente en la materia de Geografía e Historia, en la Educación Secundaria.

\section{PLANTEAMIENTO}

Como "las erupciones volcánicas tienen un gran impacto en el clima terrestre en las fechas sucesivas" (Fernández-Fernández et al, 2005, p. 1), y teniendo en cuenta que algunos autores especializados en el estudio de eventos eruptivos proponen que "la única vía para aproximarnos a una previsión lógica sobre el «tipo de erupción» es el estudio detallado de la historia eruptiva" (Araña y Ortiz, 1993, p. 279), el objetivo de esta obra es desarrollar una estrategia educativa que englobe aspectos esenciales del proceso de enseñanza y aprendizaje de la Geografía y la Historia, a través del análisis de las consecuencias causadas por una serie de eventos catastróficos de origen volcánico, en diferentes momentos históricos. Este hecho ha llevado a plantearnos cuál ha sido la influencia de estos acontecimientos en los años posteriores a un evento eruptivo concreto, es decir, si una supererupción volcánica puede cambiar el rumbo de la historia, ¿cuántas veces habría pasado? Pero sobre todo, ¿sería posible estudiar las etapas de la Historia, momentos destacados del Arte y determinados aspectos geográficos, a travé de estas grandes erupciones? Así, si el estudio de la historia eruptiva de un evento volcánico del pasado sirve para prevenir futuros cataclismos eruptivos, ¿por qué no pueden ser de utilidad en el estudio de acontecimientos históricos y geográficos en el mundo académico?

Para ello, los siguientes apartados indagarán en algunos acontecimientos eruptivos que han podido influir de manera directa o indirecta en la evolución de la sociedad humana, proporcionando las claves para comprender la trascendencia volcánica en eventos geográficos, pero sobre todo, históricos y artísticos (e incluso en diversas disciplinas de las Ciencias Sociales y las Humanidades). Por ello el objetivo final es la presentación de una propuesta didáctica, usando los eventos volcánicos más destacados como eje vertebrador del aprendizaje autónomo por parte del alumnado (dentro del espacio educativo y mediante la intervención de diferentes materias).

\section{LOS VOLCANES EN EL MUNDO ACADÉMICO}

El estudio de los volcanes en el mundo académico tiene grandes carencias, ya que conserva un contenido escaso, un tratamiento transversal nulo y poco provecho social. Por un lado, "es un clásico de los temarios de Ciencias Naturales" (Pujadas et $a l, 1999$, p. 200), entre los que se encuentra la Geología (asignatura que tiene muy poca presencia en el currículo actual). Y por otro lado, su presencia en temarios de 
las Ciencias Sociales o las Humanidades, sobre todo en asignaturas como la Geografía (muy propicia para el estudio en sus ramas físicas), es prácticamente inexistente. Y mucho más si hablamos de asignaturas como la Historia o la Historia del Arte (siendo en este caso más comprensible). Sin embargo, "la popularidad de los volcanes -junto con los terremotos- supera con mucho la esfera docente para alcanzar, en la calle, el papel de fenómeno geológico por excelencia" (Pujadas et al., 1999, p. 200).

Uno de los principales problemas del estudio normativo de los volcanes en el mundo académico tiene que ver con el uso común de clasificaciones tradicionales, hoy en día obsoletas. En éstas, para cada tipo de actividad volcánica existen diferentes procesos eruptivos (dependientes de diversas variables físicas), una serie de morfologías características y materiales expulsados por la boca eruptiva (catalogados y definidos de muchas maneras, según el autor).

Sin embargo, como expone Pujadas et al. (1999), en las clasificaciones tradicionales se suelen utilizar más «calificativos» que «clasificaciones», ya que "algunos utilizan los nombres de volcanes aislados (vulcaniano), otros atribuyen cierta afinidad a la actividad eruptiva de toda una zona volcánica (hawaiiano) o incluso se basan en personajes de la historia (pliniano)" (Pujadas et al., 1999, p. 204). No obstante, en "la práctica docente convendría utilizar una clasificación genérica lo más común posible, evitando la sistemática basada en ejemplos localistas" (Pujadas et al., 1999, p. 204). Por ello, atendiendo a una de las clasificaciones más tradicionales, y usando aspectos comunes y generales (como la temperatura), nos encontramos que el estilo hawaiiano y el estromboliano atiende a características más efusivas del material (como consecuencia de la mayor temperatura del magma), mientras que el resto de dinamismos, es decir, el vulcaniano, peleano o pliniano, alcanzan una menor temperatura y fluidez del magma, y por lo tanto, éste genera un mayor grado de explosividad (expulsando gran cantidad de materiales piroclásticos, como la ceniza).

\section{LOS VOLCANES, ENTRE LA SOCIEDAD Y LA HISTORIA}

Como ya hemos visto, el tipo de actividad eruptiva es muy variado, existiendo volcanes relativamente apacibles (como los hawaianos), otros temibles (como los estrombolianos), e incluso algunos ostentan un poder tan destructivo que han marcado la vida en La Tierra (como los plinianos o vulcanianos). Entre este último tipo de volcanes caben destacar los volcanes compuestos (también conocidos como estratovolcanes), y los supervolcanes (formados generalmente por grandes calderas eruptivas), con un índice de explosividad volcánica muy elevado. Así, según Cano (1994), Prohom (2001) y Pujadas et al. (1999), estos volcanes pueden expulsar a la atmósfera una enorme cantidad de gases (como el dióxido de carbono, el dióxido de azufre y el metano) y piroclastos (como la ceniza y la cinerita).

Estos piroclastos más finos de naturaleza pulverulenta, que disminuyen de tamaño al alejarse del centro emisor, se van acumulando en la zona de difusión horizontal de la columna eruptiva (entre la troposfera y la estratosfera). Este fenómeno provoca inicialmente un proceso de calentamiento global (debido al efecto del $\mathrm{CO}^{2}$, pero sobre todo del $\mathrm{SO}_{2}$ y el metano), y posteriormente, un enfriamiento como consecuencia del taponamiento de la radiación solar que llega a la superficie 
terrestre. Según la zona de la erupción, estos efectos pueden tener una duración mayor o menor, dependiendo del tiempo que permanece en suspensión el material piroclástico y de la circulación atmosférica del lugar (pudiendo ser de entre 2 y 3 años).

Sin embargo, la correlación entre la vida y los volcanes puede ser un proceso amplio y muy antiguo (en algunas ocasiones solo comprensible a escala geológica). Sirva como ejemplo un hecho relacionado con los volcanes, que influyó de manera decisiva en la evolución de la vida en La Tierra, y que se produjo hace aproximadamente 600 millones de años (durante el Cámbrico). En ese período, y como consecuencia de una serie de erupciones volcánicas, las bacterias sufrieron una concatenación de modificaciones adaptativas a su nuevo entorno, creando membranas como mecanismo de protección, pasando así al siguiente paso evolutivo, los organismos multicelulares.

Ya en épocas más recientes, la relación entre los volcanes y la sociedad humana también ha derivado en profundos cambios para la especie, ya que en el transcurso de la historia "han tenido lugar numerosas erupciones destructivas durante los últimos miles de años, (...) algunas de las cuales pueden haber influido en el curso de la civilización" (Tarbuck et al., 2005, p. 149). Este período engloba desde la aparición de los primeros homínidos (hace aproximadamente 5 millones de años) hasta épocas más contemporáneas, período donde se han producido algunos de los eventos eruptivos más trascendentes de la historia.

Durante estos últimos miles de años han entrado en erupción volcanes con una magnitud eruptiva muy elevada, como la caldera de Yellowstone (en el estado norteamericano de Wyoming) hace unos 2,2 millones de años, la caldera de Long Valley (también en Norteamérica, en el estado de California) hace 760.000 años, o la caldera del Lago Toba (en la isla indonesia de Sumatra) hace entre 75.000 y 69.000 años.

También durante el período de las primeras civilizaciones humanas destacan las erupciones del Tera (en la actual isla de Santorini, en el mar Egeo) en torno al año 1600 a.C., el volcán Hekla (localizado en la isla nórdica de Islandia) o el famoso volcán Vesubio (cercano a la ciudad italiana de Nápoles) en el año 79 d.C., y relacionado con los Campos Flégreos.

Finalmente, en los últimos 500 años de historia, destaca el volcán Huaynaputina (en el actual Perú) en torno al año 1600 d.C., el Laki (en Islandia) en el año 1783, el Tambora (en la isla indonesia de Sumbawa) en el año 1815, el Krakatoa (situado entre Java y Sumatra, en el archipiélago indonesio) en el año 1883, el Monte Pelée (en la isla caribeña de Martinica), el Saint Helens (en el estado norteamericano de Washington), el Nevado del Ruiz (en Colombia), el Pinatubo (en Filipinas) y, en último lugar, el Eyjafjallajökull (en Islandia) en el año 2010.

Estos eventos eruptivos suponen un contenido histórico y geográfico fundamental, derivando en nuevos puntos de vista historiográficos de acontecimientos históricos, sociales y artísticos en el mundo académico, cuyos modelos más destacados serán expuestos a continuación. 


\section{Figura 1. Localización de los principales eventos volcánicos catastróficos que sirven como ejemplos para el Proyecto.}

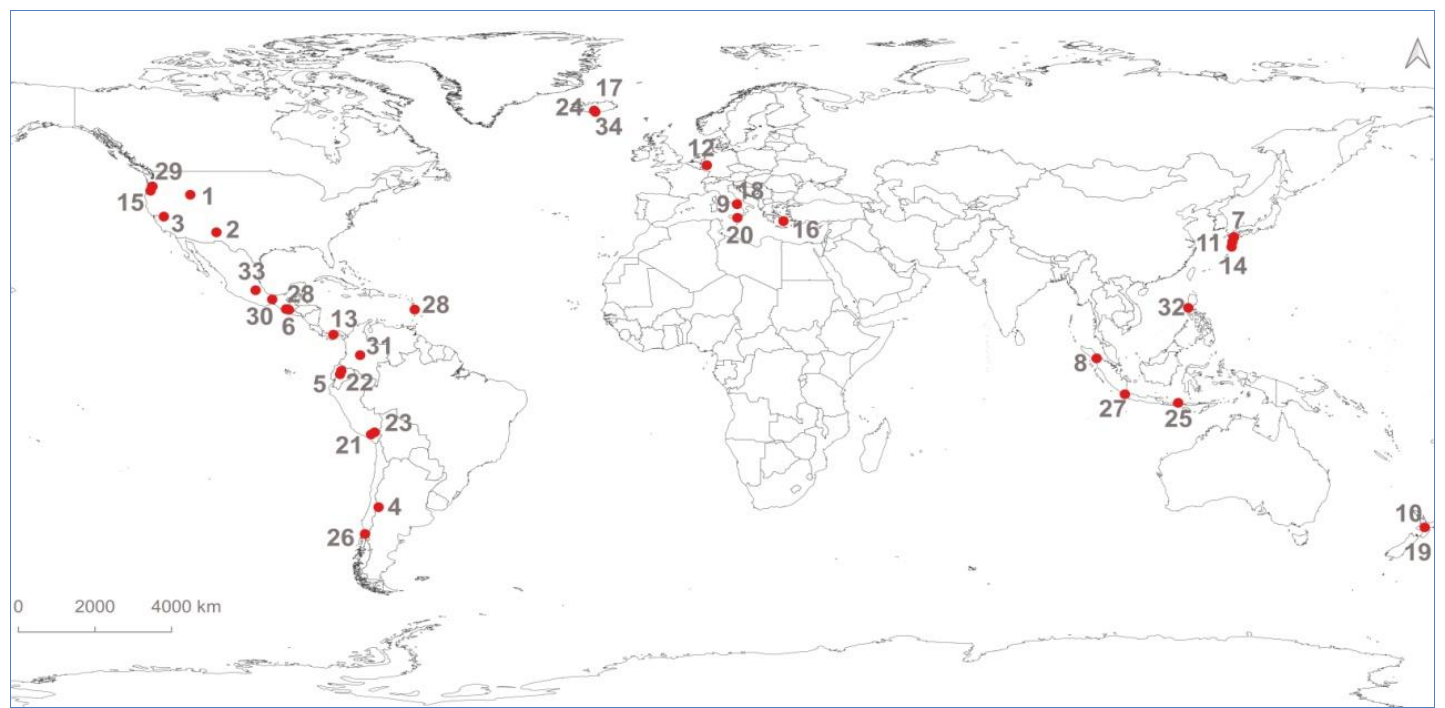

Fuente: Elaboración propia. № 1: Caldera Yellowstone, Wyoming, EE.UU. (2’2 m.a.). N 2: Valle Grande, Nuevo México, EE.UU. (1'12 m.a.). No 3: Caldera Long Valley, California, EE.UU. (760.000 años). $N^{\circ}$ 4: Caldera Diamante, Argentina (500.000 años). № 5: Caldera El Chalupas, Ecuador (200.000 años). № 6: Caldera Atitlán, Guatemala (84.000 años). № 7: Monte Aso, Kyushu, Japón (80.000 años). $N^{\circ}$ 8: Caldera del Toba, Sumatra, Indonesia (75.000-69.000 años). N$^{\circ}$ 9: Campos Flegreos, Italia (40.000 años). № 10: Volcán Taupo, Nueva Zelanda (26.500 años). $\mathrm{N}^{\mathbf{0}}$ 11: Caldera Aira, Kyushu, Japón (22.000 años). № 12: Laacher See, Alemania (12.900 años). № 13: Valle de Antón, Panamá (10.000 años). N ${ }^{\circ}$ 14: Caldera Kikai, Kyushu, Japón (6.300 años). N $^{\circ}$ 15: Monte Mazama, Oregón, EE.UU. (4.860 años). N 16: Tera, Santorini, Grecia (1628 aC). № 17: Hekla, Islandia (1150 - $1136 \mathrm{aC})$. N $\mathrm{N}^{\circ}$ 18: Vesubio, Nápoles, Italia (79 dC). № 19: Volcán Taupo, Nueva Zelanda $(181 \mathrm{dC}) . \mathrm{N}^{\circ}$ 20: Etna, Sicilia, Italia $(1169 \mathrm{dC}) . \mathrm{N}^{\circ}$ 21: Misti, Perú $(1450 \mathrm{dC}) . \mathrm{N}^{\circ} \mathbf{2 2}$ : Pichincha, Ecuador y Misti, Perú (1575 dC). No 23: Huanynaputina, Perú (1600 dC). № 24: Laki, Islandia (1783 dC). № 25: Tambora, Sumbawa, Indonesia (1815 dC). № 26: Volcán Osorno, Chile $(1835 \mathrm{dC}) . \mathrm{N}^{\circ}$ 27: Krakatoa, Indonesia $(1883 \mathrm{dC}) . \mathrm{N}^{\circ}$ 28: Monte Pelée, Martinica y Santa María, Guatemala (1902 dC). № 29: Saint Helens, Washington, EE.UU. (1980 dC). No 30: Chichonal, Chiapas, México (1982 dC). № 31: Nevado del Ruíz, Colombia (1985 dC). № 32: Pinatubo, Filipinas (1991 dC). N 33: Popocatépetl, México (1997 dC). No 34: Eyjafjallajökull, Islandia (2010 dC). La ausencia de episodios en el continente africano y en la península de Kamchatka es consecuencia de la falta de fuentes o dataciones de posibles eventos.

\section{La erupción del volcán del lago Toba (en la Prehistoria)}

Para muchos vulcanólogos, la erupción más catastrófica de la historia humana tuvo lugar en el actual lago Toba, en la isla de Sumatra (Indonesia), cuya fecha aproximada está datada entre 75.000 y 69.000 años. En estos períodos, entre las dos principales especies que habitaban La Tierra estaba el Neandertal y el Homo Sapiens, coetáneos hasta la desaparición del primero hace aproximadamente 28.000 años. En cambio, investigaciones más recientes demuestran que "algunos grupos de Homo Erectus coexistieron con el Homo Sapiens, incluso después del Toba. El Homo javaensis, vivió en Java hace tan solo 25.000 años y el Homo floresiensis sobrevivió en Flores hasta hace unos 12.000 años" (Weber, 2007). 


\section{Cuadro1. Lista de episodios volcánicos cataclísmicos seleccionados y su relación histórica.}

\begin{tabular}{|c|c|c|}
\hline Etapas & Episodio cataclísmico y fecha & Etapa y relación histórica \\
\hline 1 & $\begin{array}{c}\text { Volcán Toba }\left(n^{0} 8\right) \text {, } \\
\text { hace unos 75-69 mil años }\end{array}$ & $\begin{array}{c}\text { Prehistoria: Neandertal y Sapiens. Desaparición } \\
\text { del } 90 \% \text { de la población. }\end{array}$ \\
\hline 2 & $\begin{array}{c}\text { Volcán Tera, } \\
\text { actual Santorini }\left(\mathrm{n}^{\circ} 16\right) \text {, } \\
\text { en el siglo XVII aC }\end{array}$ & $\begin{array}{l}\text { Prehistoria y Edad Antigua: Antigua Grecia. } \\
\text { Desaparición de la civilización minoica y } \\
\text { posible mito de la Atlántida. }\end{array}$ \\
\hline 3 & $\begin{array}{l}\text { Volcán Hekla }\left(\mathrm{n}^{0} 17\right) \text {, } \\
\text { En el siglo XII aC }\end{array}$ & $\begin{array}{l}\text { Edad Antigua: afectación hasta China. } \\
\text { Literatura (Julio Verne). }\end{array}$ \\
\hline 4 & $\begin{array}{l}\left.\text { Volcán Vesubio ( } \mathrm{n}^{0} 18\right) \text {, } \\
\text { en el siglo I dC }\end{array}$ & $\begin{array}{c}\text { Edad Antigua: Imperio Romano. Destrucción } \\
\text { de Pompeya y Herculano. }\end{array}$ \\
\hline 5 & $\begin{array}{l}\text { Volcán Huaynaputina }\left(\mathrm{n}^{\circ} 18\right) \text {, } \\
\text { a principios del siglo XVII dC }\end{array}$ & $\begin{array}{l}\text { Edad Moderna: Felipe III (Austria menor). } \\
\text { Hambrunas por todo el mundo. }\end{array}$ \\
\hline 6 & $\begin{array}{l}\left.\text { Volcán Laki ( } \mathbf{n}^{\circ} 23\right) \text {, } \\
\text { a finales del siglo } \\
\text { XVIII dC }\end{array}$ & $\begin{array}{l}\text { Edad Moderna y Contemporánea: Revolución } \\
\text { Francesa e Industrial. Malas cosechas, } \\
\text { hambrunas, epidemias, revoluciones sociales, }\end{array}$ \\
\hline 7 & $\begin{array}{c}\left.\text { Volcán Tambora ( } \mathrm{n}^{0} 24\right) \text {, } \\
\text { de principios del siglo } \\
\text { XIX dC }\end{array}$ & $\begin{array}{l}\text { Edad Contemporánea: Liberalismo en España. } \\
\text { Malas cosechas, hambrunas, epidemias, obras } \\
\text { literarias, de arte e inventos. }\end{array}$ \\
\hline 8 & $\begin{array}{l}\text { Volcán Krakatoa (no } 26) \text {, } \\
\text { de finales del siglo XIX dC }\end{array}$ & $\begin{array}{c}\text { Edad Contemporánea: Restauración borbónica. } \\
\text { Obras de arte. }\end{array}$ \\
\hline 9 & $\begin{array}{l}\text { Volcán Saint Helens ( } n^{0} \text { 28) } \\
\text { y Eyjafjallajökull }\left(n^{\circ} 33\right) \\
\text { en el siglo XXI dC }\end{array}$ & $\begin{array}{l}\text { Edad Contemporánea: Efectos de la } \\
\text { globalización. Sistemas de prevención, efecto } \\
\text { en el tráfico aéreo y la economía de Europa. }\end{array}$ \\
\hline
\end{tabular}

Fuente: Elaboración propia.

Pero, según la teoría denominada la Catástrofe de Toba, propuesta por Stanley $\mathrm{H}$. Ambrose, la magnitud de la erupción del Toba fue tan grande que "se cree que redujo la población humana en un $90 \%$ y provocó un invierno volcánico que duró seis años" (Pérez-Folgado, 2014, p. 213). En esta controvertida teoría se menciona el denominado «cuello de botella poblacional o genético», es decir, "una reducción seria en el número de miembros vivos de una especie en algún momento en el pasado" (Weber, 2007). Si una parte importante de una población desaparece, existe una pérdida forzosa de diversidad genética entre los que sobreviven. Sin embargo, no todos los científicos están de acuerdo con esta teoría. Para algunos, estando de acuerdo con el denominado «cuello de botella genético», este fenómeno debió de producirse en un pasado más alejado de la Historia humana (previo al Toba). 
No obstante, para muchos otros científicos, las pruebas son suficientes para aceptar el momento de la erupción del Toba, como el inicio del designado «cuello de botella» en el género Homo. Si ya es difícil reconocer un cuello de botella en una especie, mucho más tener que identificar la intensidad, la duración y, sobre todo, la fecha de cuándo se produjo, debido a que las causas de estos fenómenos reductores de población son muy variadas. Según Weber (2007), pueden ser consecuencia de una epidemia, de un depredador muy efectivo, o como en el caso del Toba, un cambio climático como consecuencia de una supererupción volcánica.

Pero partiendo de esta teoría, y tal como comenta Weber (2007), durante varios millones de años previos al cuello de botella del Toba, existieron varias especies de homínidos análogas, con grandes cerebros y andar erguido. Sin embargo, hace unos 100.000 años, el género Homo esparció sus territorios de caza fuera de África, a través del valle del Nilo hasta el Mediterráneo (con el Heidelbergensis, el Neandertal y el Sapiens), y a través de la península del Sinaí, hasta el oeste de Asia (con el Erectus y el Sapiens). Por ello, la distribución geográfica del género Homo hace 75.000 años contribuyó a una exposición elevada a los efectos directos e indirectos del Toba, a diferencia de otras especies de simios. No obstante, de las cuatro especies del género Homo que lograron atravesar el cuello de botella, solo queda el Homo Sapiens.

\section{La erupción del Tera (al principio de la Edad Antigua)}

El Tera fue un supervolcán de la antigüedad, situado en el Mar Egeo, en la actual isla de Santorini (Grecia). Su episodio eruptivo más conocido tuvo lugar alrededor del año 1628 a.C., en el que

"una tremenda columna de humo y cenizas alcanzó los $30 \mathrm{Km}$. de altura convirtiendo el día en noche, en centenares de kilómetros; se produjo una ola gigantesca (tsunami), que superó los $50 \mathrm{~m}$. de altura y que asoló Creta. Las colosales detonaciones pudieron oírse en puntos tan alejados como el centro de África -los antiguos egipcios registraron los datos de aquella erupción-, Escandinavia, el Golfo Pérsico o Gibraltar. El polvo suspendido en la troposfera y en las capas bajas de la estratosfera probablemente alteró el clima en todo el mundo y, según se cree, este cambio contribuyó a la súbita desaparición de la civilización minoica, siendo Santorini el único volcán que haya destruido una civilización entera" (Cano, 1994, p. 233).

Por aquella época, la civilización minoica disfrutaba de un próspero desarrollo, en ciudades como Akrotiri, con "importantes avances en infraestructura y servicios, (...) como muros de ladrillos y soportes de maderas horizontales y verticales" (Ferradas, 2015, p. 81-82), numerosos avances sociales, en artesanía, comercio y muchos otros aspectos. Pese a todo ello, los pobladores no pudieron aguantar las embestidas de las fuerzas naturales y acabaron por abandonar el lugar.

Como comenta Ferradas (2015), los habitantes de esta civilización, ante la posibilidad de una inminente erupción del volcán, evacuaron los principales asentamientos. "Los estudios actuales no han encontrado restos humanos ni objetos preciosos en Akrotiri, lo que sugiere que la evacuación fue organizada y efectiva" (Ferradas, 2015, p. 82). Lo que sí parece claro es que estos establecimientos no 
volvieron a ser habitados después del cataclismo. La ciudad "quedó enterrada y sus restos permanecieron ocultos hasta 1967, cuando los arqueólogos empezaron a investigar la zona. La excavación de bellas jarras de cerámica y pinturas murales indican que (...) daban cobijo a una sociedad rica y sofisticada" (Tarbuck et al., 2005, p. 150).

Según un "escrito del filósofo griego Platón, un imperio insular llamado Atlántida fue absorbido por el mar en un día y una noche" (Tarbuck et al., 2005, p. 149). Para algunos, los sucesos acontecidos en este lugar en fechas análogas y su repentina desaparición hacen que la civilización a la que Platón hace referencia pueda ser la minoica. Incluso más allá del mito, las causas de la desaparición repentina de la civilización minoica continúan siendo un misterio, aunque "no hay duda de que una erupción catastrófica tuvo lugar en Santorini alrededor del año 1600 a. C." (Tarbuck et al., 2005, p. 149). Eso queire decir, al menos, que este cataclismo pudo ser una de las causas más plausibles de su desaparición.

\section{La erupción del Vesubio (en las fases finales de la Edad Antigua)}

La erupción del volcán Vesubio en el año 79 d. C. no se puede considerar un gran cataclismo a nivel mundial, no obstante, se trata de uno de los mejor documentados. Esto es debido a que "Plinio el joven estuvo entre los pocos sobrevivientes y narró lo sucedido, incluyendo la experiencia de su tío y los intentos de huída de la multitud" (Ferradas, 2015, p. 84). Sin embargo, su influencia, pese a ser local, ha trascendido en la Historia.

Por el año 79 d. C., el estratovolcán del Vesubio llevaba tiempo dormido, sin erupciones previas que avisaran de la inminente catástrofe, e incluso "había viñedos adornando sus solanas" (Tarbuck et al. 2005, p. 150). Este tipo de volcán puede entrar en erupción con mucha rapidez, por eso cogió a las poblaciones de sus entornos desprevenidas.

"El 24 de agosto la tranquilidad acabó y, en menos de 24 horas, la ciudad de Pompeya (cerca de Nápoles) y más de 2.000 de sus 20.000 habitantes desaparecieron. Algunos quedaron enterrados debajo de una capa de pumita de casi 3 metros de grosor, mientras otros quedaron enterrados por una capa de cenizas solidificadas. Permanecieron así durante casi diecisiete siglos, hasta que se excavó parcialmente la ciudad, dando a los arqueólogos una imagen magníficamente detallada de la vida en la antigua Roma" (Tarbuck et al., 2005, p. 150).

Además de los datos de las excavaciones de Pompeya y Herculano, los registros históricos (sobre todo escritos por Plinio el Joven), son de vital importancia en el entendimiento de este hecho histórico. Como comenta Tarbuck et al. (2005), y partiendo de los registros escritos; algunos habitantes, puede que los que vivían más alejados del volcán, se ataron almohadas a la cabeza para evitar que los piroclastos de proyección aérea les golpeasen. Igualmente, "el aire estaba tan envenenado por el olor sofocante del azufre, y había tanta ceniza que tuvieron que valerse de antorchas para ver por donde iban" (Ferradas, 2015, p. 85). Varios siglos más tarde, "la ciudad desenterrada tenía 1.150 cadáveres de personas que no alcanzaron a huir y cuyos 
cuerpos fueron hallados en tal estado que se pueden ver sus expresiones" (Ferradas, 2015, p. 85).

Para los arqueólogos, las ruinas de Pompeya constituyen un laboratorio de gran trascendencia en el estudio de uno de los períodos más importantes de la historia (la de la antigua Roma). En ellas encontramos moldes, materiales y objetos, similares a lo que se encuentran en Egipto por el proceso de momificación, debido a que

"sus restos quedaron rápidamente enterrados por la ceniza que caía, que la lluvia cimentó en una masa dura antes de que sus cuerpos tuvieran tiempo de descomponerse. La posterior descomposición de los cuerpo produjo cavidades en la ceniza solidificada que reproducen exactamente la forma de los cuerpos sepultados, (...). Los excavadores del siglo XIX encontraron estas cavidades y crearon moldes de los cadáveres echando escayola en los huecos. Algunos de los moldes de escayolas muestran víctimas que intentan cubrirse las bocas en un esfuerzo por tomar lo que sería su último aliento. (...) También los esqueletos excavados de la población cercana de Herculano indican que la mayoría de sus habitantes murieron probablemente a causa de estas coladas" (Tarbuck et al., 2005, p. 151).

Figura 2. Ruinas actuales de Pompeya.

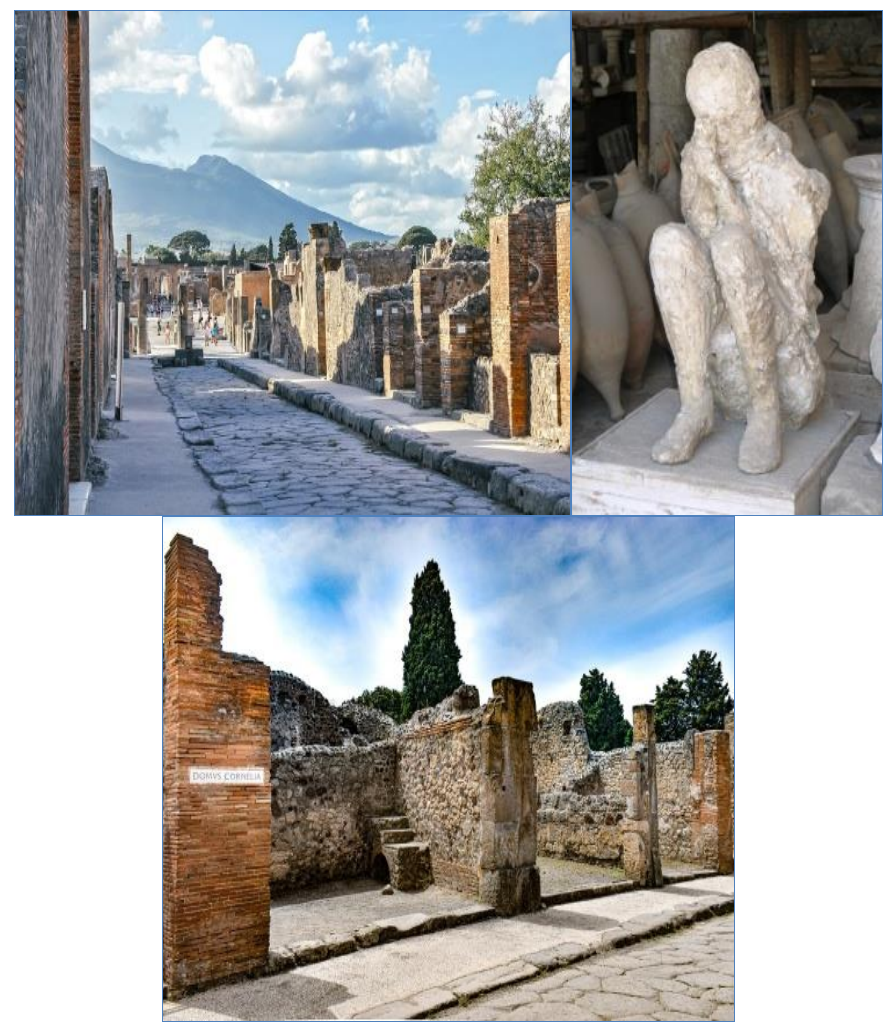

Fuente: Imágenes obtenidas de Pixabay. Imagen superior: calle de la antigua Pompeya actualmente. Imagen inferior izquierda: molde de un antiguo habitante de Pompeya tras ser sepultado por un flujo piroclástico. Imagen inferior derecha: edificios de la antigua Pompeya en la actualidad. 


\section{La erupción del Laki (transición entre la Edad Moderna y la Edad Contemporánea)}

El volcán islandés Laki, nombre que recibe por un cono volcánico cercano, está compuesto por una fractura de unos 25 kilómetros, formada por hasta 115 puntos eruptivos diferentes (Cano, 1994).

Sus efectos más inmediatos se dejaron sentir en la isla nórdica de Islandia, provocando la contaminación de los pastos y el sucesivo envenenamiento del ganado, lo que conformaba el principal sustento de la población por entonces. Según Camilloni (2008) falleció el $80 \%$ de las ovejas y el 50\% de las vacas y caballos. Este hecho hizo que la hambruna que desató fuese considerada de proporciones apocalípticas, alcanzando una mortalidad superior al $25 \%$ en la población isleña (Fúster, 2000).

En Europa, la situación aquel año provocaría fuertes anomalías climáticas durante los siguientes solsticios de invierno y verano. Así, según datos de Camilloni (2008), en Francia se llegó a constatar la muerte de hasta el 5\% de la población en ese verano. Y debido a la nube de cenizas y gases, los daños en cultivos, bosques y en el agua fueron enormes. Este hecho influyó también en el posterior aumento de enfermedades y la elevada mortandad, sobre todo en zonas rurales de Inglaterra. Según una investigación reciente,

"el verano de 1783 fue un verano muy caliente y hubo fuertes tormentas, con grandes granizos y abundantes bolas de fuego. En este continente, el invierno de 1783-1784 fue muy duro. Estas condiciones causaron problemas a la producción agrícola en el campo y desabastecimiento en las ciudades" (Cuchí, 2015, p. 160).

El invierno de 1784 fue especialmente duro en Gran Bretaña, con una mortandad de ocho mil muertes por encima de lo esperado (Camilloni, 2008). Además "se considera que Laki también provocó problemas de tipo meteorológico en Egipto e India" (Cuchí, 2015, p. 160). El descenso en la temperatura media en gran parte del Hemisferio Norte dejó constancia en datos meteorológicos y afecciones en las cosechas, y por consiguiente, en la población. Así, según algunas investigaciones,

"las temperaturas medias fueron ese invierno en Europa unos $2^{\circ} \mathrm{C}$ inferiores a las imperantes durante la segunda mitad del siglo XVIII, valor que alcanzó a $5^{\circ} \mathrm{C}$ en Islandia y el este de Estados Unidos, y a $3^{\circ} \mathrm{C}$ en Suecia y Dinamarca. También en Estados Unidos fue duro el invierno de 1784. El río Mississippi se congeló en Nueva Orleans y bloques de hielo emergieron de su desembocadura y flotaron en el golfo de México. En Japón se produjeron fríos excepcionales por tres inviernos consecutivos, con pérdida de las cosechas de arroz y la muerte de un millón de personas" (Camilloni, 2008, p. 40).

Debido a que "las cenizas y gases tóxicos dispersados por condiciones meteorológicas favorables alcanzaron casi toda Europa, incluso el sur de España y el norte de África" (Cuchí, 2015, p. 160), existen evidencias documentales de su efecto en estas regiones. Por ejemplo, en España, son varios los estudios que hablan del impacto en los años posteriores a esta erupción. Según Fernández-Fernández et al. (2005), las informaciones que le llegaban al Duque de Feria... 
"supusieron el año de 1784 como uno de los más fríos, registrándose nevadas en primavera y días muy fríos durante el verano. Por ejemplo, el día 5 de abril se informó al Duque de la nevada y las bajas temperaturas acaecidas durante esa semana. (...) Lo mismo ocurrió en los informes al Duque durante los meses de verano donde se demuestran los fríos acaecidos durante esta época del año" (Fernández-Fernández et al., 2005, p. 1).

Sin embargo, si tenemos en cuenta la cantidad de erupciones de gran magnitud en esos mismos años, el "análisis de los fenómenos climáticos relacionados con la erupción del Laki puede ser complicado, pues en el mismo año 1783 existió una importante erupción en el volcán Asama (Japón) en la que se produjo una emisión de productos volcánicos" (Fúster, 2000, p. 116). Además, "entre junio de 1783 y mayo de 1785 estuvo también en erupción el inmediato volcán islandés Grímsvötn. El 17 de febrero de 1783, también entró en erupción el Etna y, unos días más tarde, el Stromboli" (Cuchí, 2015, p. 160).

Como podemos observar, la influencia del Laki es un fenómeno difícil de investigar. Aún así, y teniendo presente el peso de otros episodios eruptivos coetáneos, la erupción del Laki sentaría un precedente en las relaciones entre el clima y los volcanes, con estudios como el de Benjamín Flanklin, "que en aquella época residía en Francia como representante de los Estados de la Unión, y tuvo la intuición genial de relacionar la calima persistente y las anomalías climáticas con las erupciones de Islandia" (Fúster, 2000, p. 116).

Figura 3. El volcán islandés Laki y sus posibles consecuencias.
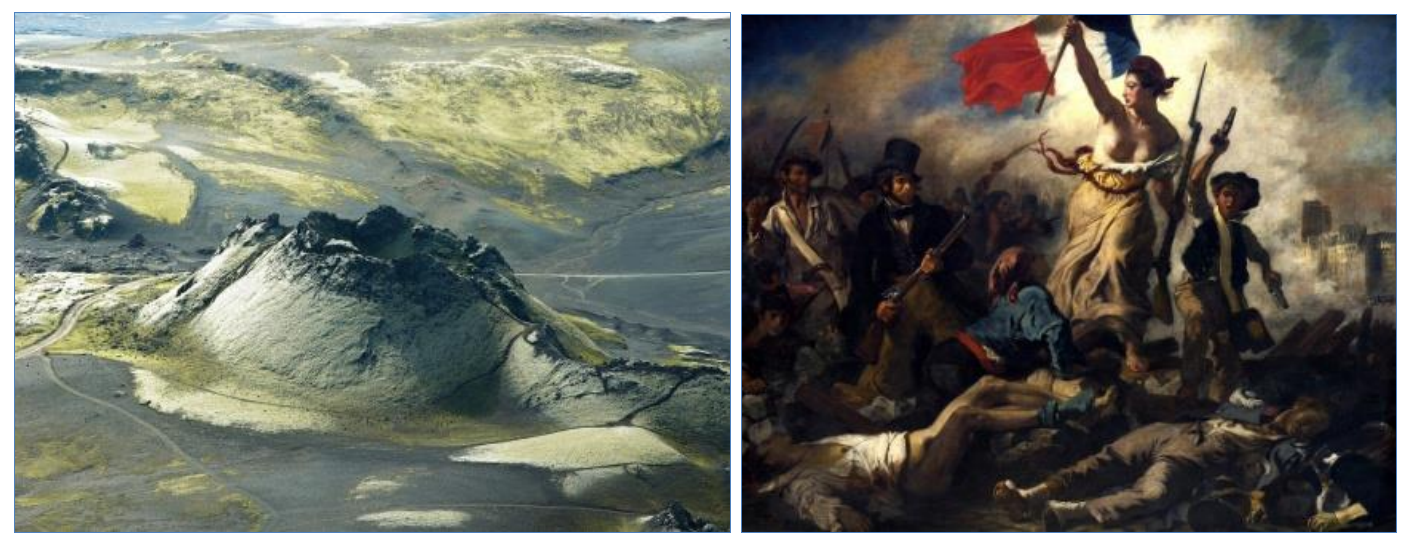

Fuente: Imágenes obtenidas de Pixabay. Imagen izquierda: vista de uno de los conos del Laki. Imagen derecha: cuadro del Romanticismo de Eugène Delacroix, denominado La Libertad guiando al pueblo.

Como hemos comentado anteriormente, Europa fue una de las regiones más afectadas. Así, a partir de 1783, Francia experimentó inviernos terriblemente fríos, tormentas eléctricas, lluvias torrenciales, granizo, y siempre en el momento en que las próximas cosechas estaban en pleno apogeo (Lamoureux, 2013). La situación de los campesinos era tan exasperada que la Revolución Francesa acabaría por estallar en 1789. Estos cambios climáticos y la erupción del Laki pueden no ser los únicos hechos implicados, pero los historiadores admiten que su influencia fue considerable en los eventos políticos que pusieron fin a la realeza (Goetelen, 2010). 
"Por supuesto, no todo fue exclusivamente climático, las circunstancias políticas tuvieron mucho que ver. (...) La situación de hambruna, la mala gestión por parte de la monarquía y el resto de estamentos privilegiados resultó asfixiante para el pueblo, que no tuvo más remedio que alzarse para sobrevivir. Pero la historia ya es ligeramente diferente, no es solo que quisiesen más derechos y se alzasen motivados fundamentalmente por las ideas ilustradas, como se suele contar tan a menudo. Si hubiesen estado todos bien alimentados, seguramente el proceso habría sido mucho más lento, dialogante, pacífico, y quién sabe si menos exitoso (en lo que respecta a iniciar el fin del absolutismo). (...) Así que, para explicar bien las causas de la Revolución Francesa, y de todo lo que vino después, como Napoleón, las guerras en Europa, y todos esos acontecimientos que sin duda tuvieron una gran repercusión en el curso de nuestra historia y en definir nuestra sociedad moderna, hay que hablar sin excusa de dos causas fundamentales: la erupción del Laki como causa de una escasez global de recursos en los años previos a la Revolución, y la mala gestión política que hubo en Francia. La expansión de las ideas ilustradas y los deseos de poder de la burguesía son un añadido que, sin duda, tuvo mucha menos influencia que el hambre en provocar el hartazgo de la población llana, aunque contribuyesen a generar la Revolución" (Flores, 2017).

\section{La erupción del Tambora (en los inicios de la Edad Contemporánea)}

La erupción del Tambora de 1815 (situada en la isla indonesia de Sumbawa) se considera uno de los episodios volcánicos más importantes de los últimos siglos, y un claro ejemplo de la influencia en aspectos artísticos y literarios. La violencia de la erupción pudo haber sido 8,4 veces más potente que la del Krakatoa, debido al taponamiento del conducto eruptivo, expulsando una cantidad enorme de material a la atmósfera (Cano, 1994). La erupción también revelaría un número significativo de víctimas directas e indirectas e importantes cambios en el clima, como así lo atestiguan numerosas publicaciones que hablan sobre «el año sin verano» de 1816.

No obstante, en este "año 1816, (...) Europa estaba destrozada por las guerras napoleónicas, que habían terminado en 1815 con la batalla de Waterloo y el exilio de Napoleón en la isla de Santa Elena" (Vergara, 2014, p. 12). Por lo tanto, es difícil conocer el número exacto de víctimas relacionadas directamente con la guerra, y las infligidas por hambrunas o enfermedades causadas por el volcán, ya que "los meteorólogos de aquel tiempo no relacionaron los efectos ópticos espectaculares con la erupción del Tambora" (Vergara, 2014, p. 12). Así, "la pérdida de cosechas, sumado a las bajas temperaturas generó una gran crisis social (...). Se sucedieron hambrunas, epidemias de cólera y tifus como la de SE de Europa y al este del Mediterráneo entre 1816 y 1819" (Vergara, 2014, p. 12).

¿Por qué fue tan importante esta erupción para la cultura? Como comenta PérezFolgado (2014), la cantidad de reseñas históricas, su influencia sobre el hemisferio norte y en la civilización occidental, junto con sus repercusiones históricas, literarias y artísticas durante el siglo XIX, suponen un importante impacto en la cultura y un gran atractivo para la enseñanza de disciplinas equivalentes en la Educación Secundaria. 
Entre los acontecimientos culturales, artísticos y científicos más destacados durante aquel «año sin verano», según Pérez-Folgado (2014), está la reunión social en la Villa Diodati, en el Lago suizo de Leman. Así, debido a las circunstancias meteorológicas especiales acontecidas aquel verano, un grupo de poetas y escritores (entre los que se encontraban Lord Byron, Mary Shelley, Percy Shelley y John William Polidori), decidieron "gastar el tiempo inventando historias de miedo y monstruos" (Pérez-Folgado, 2014, p. 214), con el objetivo de asustarse entre ellos. Así, Polidori escribiría el relato de «El Vampiro», dando origen a un nuevo género, el vampiro romántico, que se pondría de fama varios siglos más tarde. También Mary Shelley redactaría su obra más conocida, «Frankenstein». Y Lord Byron compondría el poema denominado "Oscuridad», en el que "retrata la atmósfera de ese extraño y desapacible verano sin sol" (Pérez-Folgado, 2014, p. 214).

También destacan obras de autores como el pintor inglés de paisajes William Turner, que "reflejó en algunas de sus obras extraños y bellísimos atardeceres anaranjados, que no eran sino la realidad de cómo fueron las puestas de sol de aquellos años" (Pérez-Folgado, 2014, p. 214). O el caso de inventos como el de Karl Drais, cuando en 1817 inventa la draisiana, o lo que es lo mismo, el prototipo anterior a la bicicleta moderna, que según comenta Pérez-Folgado (2014), surge como alternativa a la escasez de cebada para alimentar a los animales de tiro, principalmente a los caballos que se usaban para la carrocería del transporte de personas. Además, en años posteriores, debido a los inviernos tan duros que se habían ido prolongando, el párroco Joseph Mohr sacaría un poema que había escrito, y junto con la colaboración de un organista, le pondrían música para dar a luz a un villancico que pasaría a la historia de la navidad, conocido como «Noche de Paz» (Pérez-Folgado, 2014).

Figura 4. Obras literarias, artísticas, imaginativas y musicales relacionadas con la erupción del Tambora.

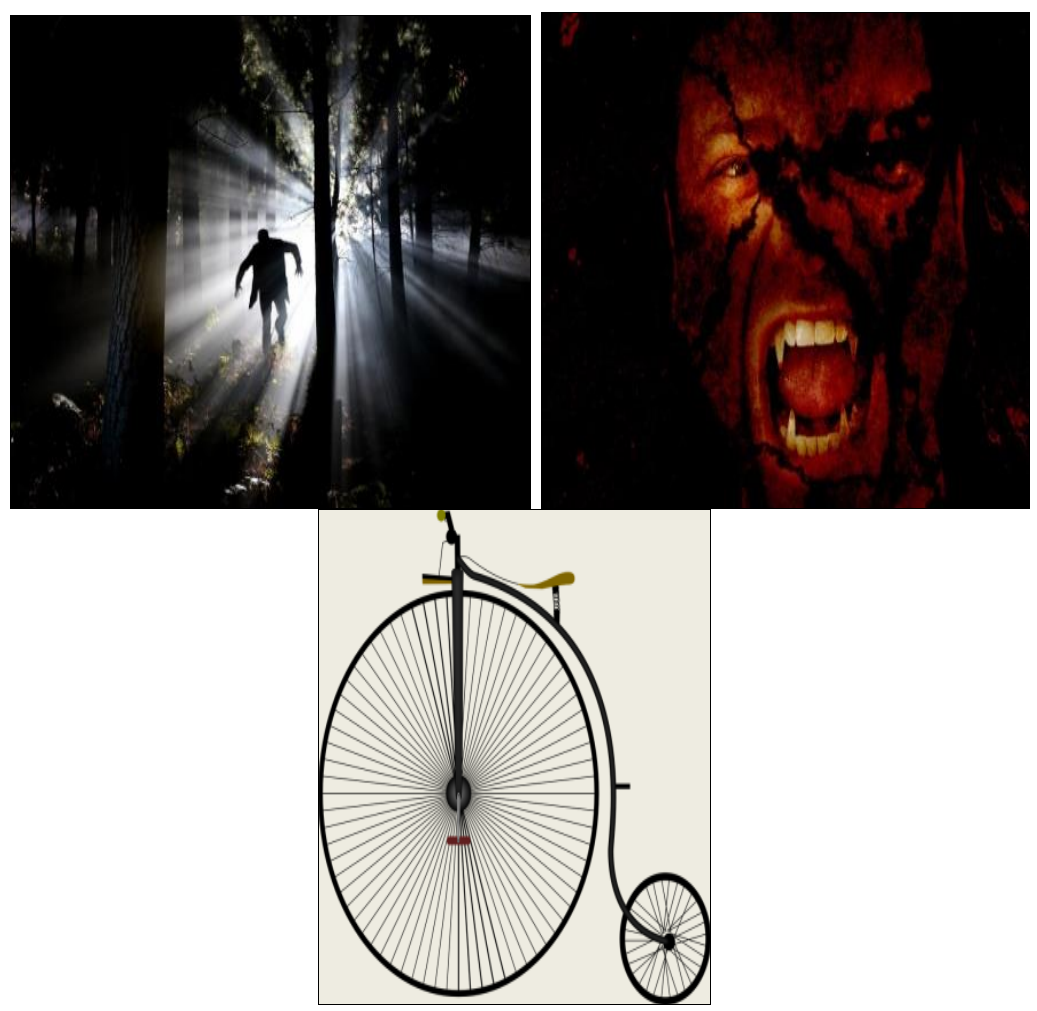



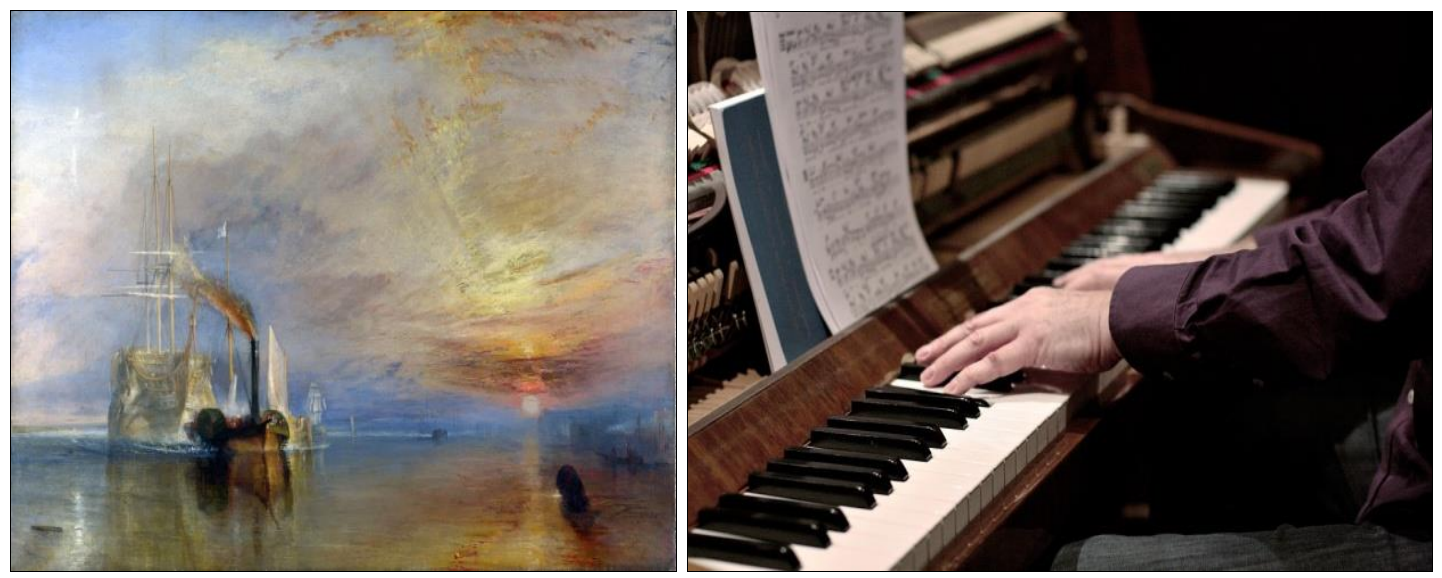

Fuente: Imágenes obtenidas de Pixabay. Imagen superior izquierda: representación de Frankenstein. Imagen superior centro: representación de El Vampiro. Imagen superior derecha: esquema de una bicicleta antigua. Imagen inferior izquierda: cuadro de William Turner, El Temerario remolcado. Imagen inferior derecha: representación de la composición del villancico, Noche de Paz.

\section{Otros episodios eruptivos}

Hasta ahora hemos visto alguno de los episodios más destacados. No obstante, existen muchos más ejemplos de la influencia de los volcanes sobre la Geografía a lo largo del planeta, sobre acontecimientos históricos a lo largo del tiempo, y sobre el devenir en la cultura, la ciencia y el arte.

Uno de los volcanes que entró en erupción con gran violencia fue el Hekla (en torno al año 1150 - 1136 a. C.). Según Cano (1994), existen documentos que hablan de su impacto en áreas tan alejadas como China, lloviendo ceniza y polvo durante los días posteriores a la erupción y generando nevadas y heladas en junio. Además, este volcán es conocido por ser el punto de entrada al interior de La Tierra en la novela de Julio Verne, denominada «Viaje al centro de La Tierra».

Otro de estos volcanes fue el Huaynaputina (en el sur de Perú), cuya erupción del año $1600 \mathrm{~d}$. C., fue de tal violencia que su influencia se sintió en prácticamente todo el globo. La insípida mezcla de gases y cenizas volcánicas cubrieron los rayos del sol impidiendo llegar la energía solar a la superficie durante varios años. Así, la erupción de este volcán sigue siendo hasta la actualidad la mayor erupción registrada en suelo sudamericano.

Su repercusión fue de una dimensión tan elevada, que los habitantes de regiones tan alejadas como Europa y Rusia nunca supieron la causa de sus miserias. Sin embargo, en años posteriores, los habitantes de Rusia vivieron uno de los peores inviernos en siglos. Durante los dos años siguientes al cataclismo, las noches de verano tenían temperaturas negativas. Su impacto fue tan grande que se cree que cerca de dos millones de personas (lo que supondría un tercio de la población rusa por entonces), morirían por la hambruna resultante y provocaría la caída del Zar Boris Godunov en 1605.

Otro ejemplo más reciente fue la cataclísmica erupción del Krakatoa, entre Sumatra y Java (en Indonesia), en el año 1883 d. C. Éste tal vez "sea uno de los volcanes más violentos y famosos del mundo, ya que (...) las ondas de choque atmosféricas que se 
produjeron se escucharon en el 7\% de la superficie terrestre" (Cano, 1994, p. 235). Pero no solo se dejaría sentir en el sonido, también

"el polvo procedente de la explosión fue propulsado a la atmósfera y circundó La Tierra (...). No obstante, la erupción no mató directamente a muchas personas, porque la isla estaba deshabitada. Sin embargo, el desplazamiento de agua como consecuencia de la energía liberada durante la explosión fue enorme. La ola marina sísmica o tsunami resultante excedió los 35 metros de altura. Arrasó la región litoral de Sunda entre las islas próximas de Sumatra y Java, inundando más de 1.000 poblaciones y llevándose más de 36.000 vidas. La energía alcanzada por esta ola alcanzó todas las cuencas oceánicas y se detectó en estaciones de registro de mareas tan lejanas como las de Londres y San Francisco" (Tarbuck, 2005, p. 153).

Como en el caso del Tambora, las consecuencias de esta erupción se dejaron sentir también en el arte. La cantidad de ceniza proyectada taparía "la luz solar de prácticamente la totalidad del planeta en tan solo 3 días; a las pocas semanas el Sol apareció «espléndidamente verde» en Sri Lanka y como «un globo azul» en Trinidad" (Cano, 1994, p. 235).

Quizás, la obra más famosa surgida de las consecuencias de este suceso sea El Grito del noruego Edvard Munch. Así,

"en 1892, un año antes de que pintara su cuadro más famoso, el artista noruego escribió en su diario lo que vio una tarde en Oslo: "de repente el cielo se tiñó de rojo. Había sangre y lenguas de fuego sobre el azul y negro del fiordo y la ciudad. Mis amigos se fueron y me quedé solo, temblando de ansiedad. Sentí un gran e interminable grito atravesando la naturaleza" (Chuet-Missé, 2020).

En la obra El Grito observamos el cielo de franjas amarillas y naranjas, al igual que la expresión de ansiedad y susto de la figura humana. Así, en este cuadro se pueden observar cada uno de los fenómenos descritos por este diario (un cielo teñido de rojo sangre, la angustia y el grito sordo del personaje). Pero, “ ¿ese cielo es una licencia artística del atardecer, o es que había un fenómeno atmosférico causado por una terrible erupción volcánica?" (Chuet-Missé, 2020). Pues según una investigación publicada en Sky and Telescope en 2003 de varios astrónomos de la Universidad A\&M de Texas, ese cielo que observó Munch era la consecuencia de la erupción del Krakatoa (Chuet-Missé, 2020). 
Figura 5. El Krakatoa y sus efectos en el arte.

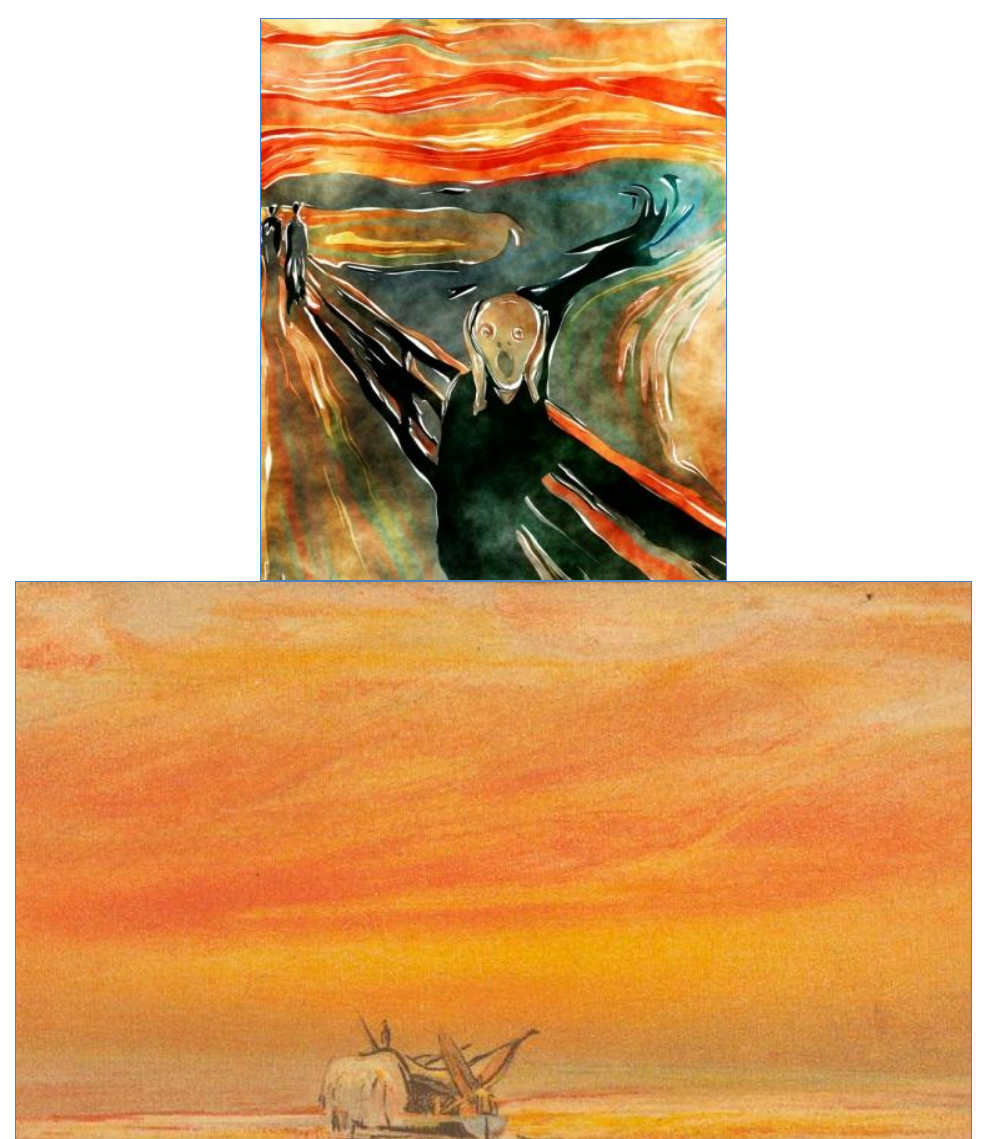

Fuente: Imagen izquierda de Pixabay: el Grito de Munch. Imagen derecha de Cerodosbe.co: Bosquejo del cielo después de la erupción del Krakatoa, de William Ascroft.

De los últimos episodios eruptivos a destacar tenemos El Monte Pelée (en la isla de Martinica, en 1902), el volcán Saint Helens (en el estado norteamericano de Washington, en 1980) y el Nevado del Ruíz (en Colombia, en 1985). En los tres casos se generarían lahares mortales que descenderían a gran velocidad por la ladera del volcán, matando a miles de personas. No obstante, estos episodios no se consideran cataclismos de gran trascendencia global.

Así, de los últimos eventos eruptivos que se tienen constancia, los más destacados a nivel global (con cierta afectación al clima o en la economía) son: el Pinatubo (en Filipinas, en 1991) y el Eyjafjallajökull (en Islandia, en 2010). Mientras que el Pinatubo "parece haber tenido un impacto significativo al influir en un posible enfriamiento de La Tierra, durante los meses posteriores, consiguiendo un retardo en el calentamiento originado por nuestra actual forma de vida" (Cano Sánchez, 1994, p. 237), el impacto del Eyjafjallajökull fue más bien económico. Durante la erupción de este último, una nube de ceniza (mezclada con vapor de agua, al derretirse el glaciar que tapaba la parte superior del volcán), provocaría el colapso del sistema aéreo de casi toda Europa. Durante los siguientes días se llegaron a cancelar muchas de las rutas aéreas, e incluso el cierre total de la actividad en aeropuertos como el de Heathrow, en Londres. 


\section{MODELO EDUCATIVO (PROPUESTA METODOLÓGICA Y FASES)}

Como se ha visto hasta ahora, los volcanes poseen una elevada influencia en aspectos económicos, sociales, demográficos, políticos e incluso artísticos. Por ello, los volcanes pueden ser grandes transformadores sociales, modificadores del paisaje, reformadores de las actividades humanas y, sobre todo, reguladores del clima. En este sentido, y "asociado a este tiempo inusual, tenemos consecuencias socioeconómicas que se traducen en malas cosechas, malnutrición e incluso enfermedades y epidemias en las zonas afectadas (Fernández-Fernández et al, 2005, p. 1). Por lo tanto, "en regiones muy dependientes de su producción agrícola, una caída importante de rendimientos era a menudo suficiente para provocar hambrunas y disturbios sociales que muchas veces eran más mortíferos que los causados directamente por las erupciones volcánicas" (Fúster, 2000, p. 115). Por eso, muchos de los episodios volcánicos catastróficos de la historia, según Fúster (2000), son seguidos por otros períodos de oscurecimiento o disminución de la energía solar en fechas posteriores a dicha erupción, a los que generalmente proseguían épocas con temperaturas más bajas, provocando la pérdida de dichas cosechas.

Como los volcanes pueden marcar el devenir de la vida, y por consiguiente, de la civilización, constituyen un fenómeno con marcado carácter didáctico en materias como la Historia, el Arte y la Geografía. En ese sentido, este tipo de contenido genera mayor motivación en el alumnado, al estudiar la relación entre la espectacularidad de un acontecimiento catastrófico y sus consecuencias históricas, la intervención autónoma de dicho estudio y el componente transversal entre varias materias. Pero no solo constituyen un elemento didáctico axial para el alumnado, sino que desde el punto de vista docente establece mecanismos y variables apropiados en el proceso de enseñanza. En este sentido se acentuarán aspectos como la inclusión social (intrínseco al objeto de estudio), el desarrollo de competencias directamente relacionadas con la materia, la autonomía (mediante el transcurso de la investigación), y todo ello desembocará en un aprendizaje significativo, motivacional y crítico. Siendo, uno de los elementos más destacados, la unión de envolturas históricas, geográficas y artísticas, bajo una misma disciplina académica, la asignatura de Geografía e Historia.

\section{La modelización}

El modelo establece dos estrategias educativas principales; por un lado, el Aprendizaje Basado en Proyectos (que no debemos confundir con el Aprendizaje Basado en Problemas), y que se desarrolla en tres fases distintas, a través del que gira toda la propuesta. Y, por otro lado, el Aprendizaje Basado en Cuentos Infográficos (que queda incluido dentro del Proyecto y es elaborado durante una de las fases).

Aunque puedan parecer similares, el tipo de estrategia didáctica apoyada en el Aprendizaje Basado en Proyectos (desde ahora ABP) posee unas características diferentes al Aprendizaje Basado en Problemas (también conocido en la terminología científica o pedagógica como ABP). Así, en el caso de este último, su principal objetivo es solucionar un inconveniente en particular (un problema o reto concreto), mientras que el Proyecto compone una condición de aprendizaje más desarrollada y extensa, en la cual se pretende atender problemas específicos, al mismo tiempo que puede ocuparse de otras áreas más amplias (Martí et al., 2010). Se puede decir que el 
Aprendizaje Basado en Proyectos puede contener en su interior el Aprendizaje Basado en Problemas.

El Proyecto es "un conjunto de tareas basadas en la resolución de preguntas o problemas a través de la implicación del alumnado en procesos de investigación de manera relativamente autónoma que culmina con un producto final presentado ante los demás" (Sánchez, 2013, p. 1). Sin embargo, esta definición se queda corta a la hora de incluir otros aspectos, o de comparar y explicar las diferencias con otras estrategias similares. Por ello, Sánchez (2013), propone una definición que consiste en detallar el ABP partiendo de la base de que

"no son aquellos en los que los estudiantes aprenden cosas que no están en el currículo (proyectos de enriquecimiento), independientemente de lo atractivos o motivadores que resulten para los alumnos. (...) Los proyectos deben ser el centro del currículo, no algo periférico. (...) Así, el ABP es el método a través del cual los alumnos pueden aprender los contenidos de una manera diferente a la instrucción tradicional. (...) No se trata de aquellas tareas que se hacen al final de la unidad para permitir a los alumnos pasar un buen rato. Es decir, (...) no es un conjunto de actividades atadas todas juntas bajo un tema o concepto, sino un conjunto de experiencias y tareas de aprendizaje, en torno a la resolución de una pregunta conducta, un problema o un reto. (...) el ABP no es sinónimo de aprender haciendo, o trabajar con las manos, ya que aunque con frecuencia se utiliza la creación de productos, su principal característica implica tareas que sean un reto intelectual, basados en la investigación, la lectura, la escritura, el debate y las presentaciones orales" (Sánchez, 2013, p. 1-2).

Por ello, algunas características que definen el ABP tienen que ver con la investigación autónoma por parte del alumnado, la adaptación por parte del docente del espacio para la investigación y la labor de guía u orientador del aprendizaje. Este proceso permite que el docente amplíe su propio conocimiento de la materia, del proceso y de su alumnado (diagnosticando problemas). Además, el proyecto contiene un alto grado multidisciplinar (relacionando materias como la Geografía, la Historia, el Arte, la Geología, la Literatura, la Tecnología, la Física y la Química). Así, este tipo de enseñanza se centra en el estudiante y promueve la automotivación, además de originar un aprendizaje colaborativo, cooperativo y significativo (ya que promueve la implicación social). Al mismo tiempo genera amplios conocimientos de la materia en el alumnado de manera individual y grupal. Pero no solo eso, también ocasiona un alto grado de dinamismo en el docente (con mejoras, nuevas aportaciones, material novedoso o alternativo), además de emprender una serie de actividades intelectuales para resolver mediante estrategias alternativas válidas, que ayuden en el desarrollo.

Finalmente, el Proyecto tiene como objetivo la elaboración de un producto, que consiste en una infografía (incluyendo viñetas de cómic) que resuma la información. Además, ésta servirá como base de la presentación oral de un «cuento» basado en evidencias y pruebas históricas, denominado como Aprendizaje Basado en Cuentos Infográficos (desde ahora ABCI). Así, aunque los cuentos "se pueden considerar como una pequeña narración breve de carácter ficticio protagonizada por un grupo reducido de personajes y que normalmente tienen un argumento sencillo" (Pérez et al., 2013, p. 4), en esta ocasión se basan por completo en la realidad histórica, cuyo 
contenido se conseguirá a través de los datos obtenidos de la investigación previa. Aunque "los cuentos pueden narrar tanto hechos reales como fantásticos, la base de la que surge el cuento suele ser algún hecho simbólico" (Pérez et al., 2013, p. 4).

El uso del cuento es importante en el proceso interdisciplinar, ya que resulta "una herramienta muy útil para trabajar diversas áreas y contenidos" (Pérez et al., 2013, p. 4), y sobre todo, para el desarrollo de la competencia lingüística, ya que "uno de los elementos más importantes de la educación es la comunicación y, precisamente, el cuento es un elemento que nos puede ayudar a conseguirla" (Pérez et al., 2013, p. 4). Todo esto ayudará a obtener un aprendizaje más significativo y motivacional en el alumnado, y "esto beneficia al aprendizaje, pues recuerdan contenidos que no recordarían si se les hubiesen transmitido de forma teórica y memorística" (Pérez et al., 2013, p. 4). Además, durante la investigación, entre otras, se deben usar las nuevas tecnologías educativas y la ludificación (permitiendo el desarrollo de la competencia digital, tan necesaria hoy en día). Conjuntamente, este tipo de enseñanza forja una capacidad crítica en el alumnado sobre el contenido, los procesos y las posibles mejoras. Para ello es esencial la elaboración de la autoevaluación, entre todos los agentes presentes.

\section{Las fases}

La base de esta propuesta didáctica se fundamenta en el tratamiento de una metodología asentada en el ABP, y que contiene el ABCI, cuyo nombre es Volcanes en la Historia (presentada a partir de tres fases). Para ello se presentan varios procedimientos a desarrollar (como investigar, narrar, crear, jugar, reconocer, analizar y criticar) y diferentes recursos (como los vídeos, los mapas, los libros, los relatos, los audios, los periódicos, las revistas e internet).

Al principio, durante la FASE A (cuyo procedimiento es individual), tiene lugar una investigación autónoma de los acontecimientos relacionados con los grandes cataclismos eruptivos, los aspectos geográficos (correspondientes a la actividad volcánica y el cambio climático) y la influencia en los distintos artistas y sus obras. A pesar de que el alumnado sabrá de antemano a qué grupo pertenece, la investigación inicial se debe llevar a cabo de manera individual. Así, tras finalizar el proceso de investigación autónoma, llegará el momento de ordenar esa información. Para ello, junto con los miembros de cada grupo, se relaciona el acontecimiento volcánico (y sus consecuencias), con las distintas etapas históricas a las que pudo haber influido, explicando cada una de ellas en profundidad. Finalmente, se reúnen por grupos y resumen los datos recopilados en el conjunto. 
Figura 6. Recopilación de la información y resolución de preguntas o problemas por medio de la investigación.

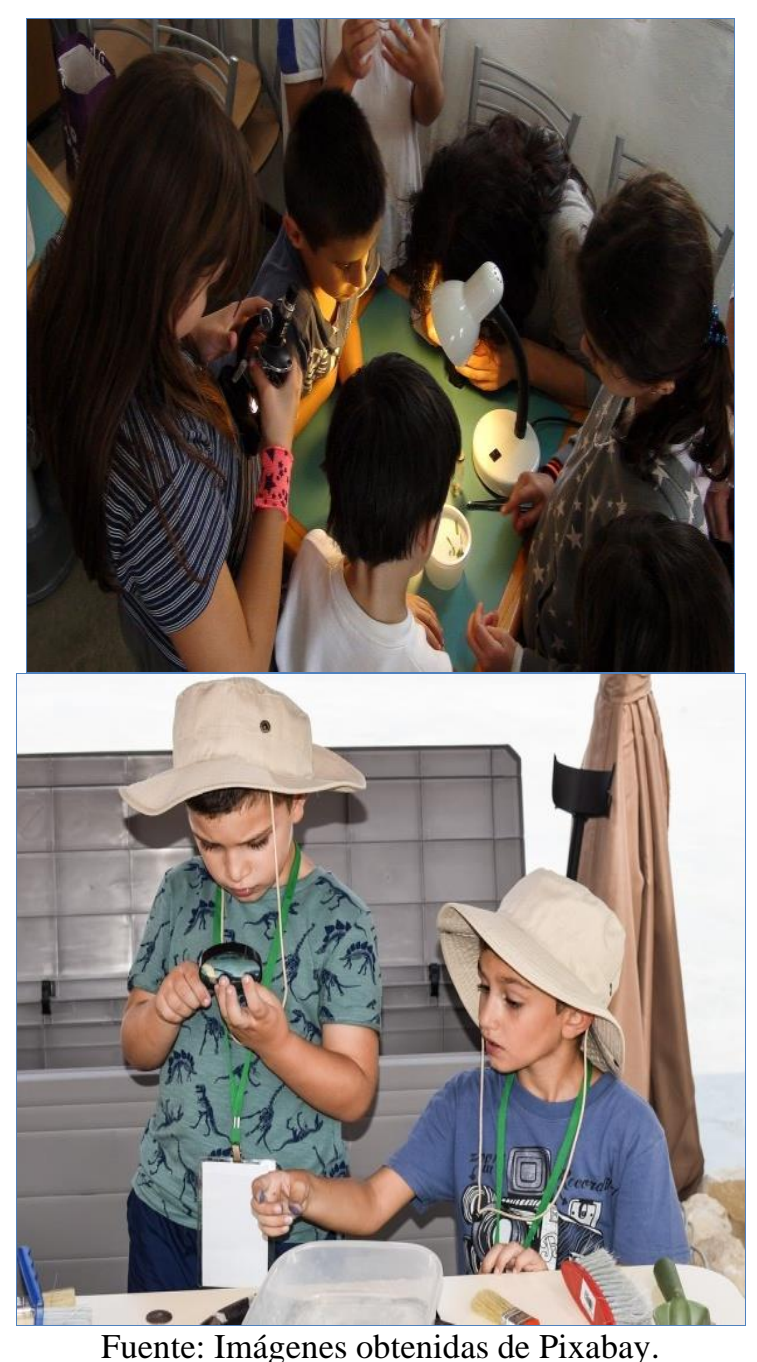

A continuación tiene lugar la FASE B (cuyo procedimiento es grupal, creativo y reflexivo). Ésta consiste en repartir roles para realizar una serie de actividades, juegos y tareas, con el objetivo final de crear las infografías necesarias para la última fase. Además, éstas podrán ser fotocopiadas y repartidas al final del Proyecto, es decir, forman parte de un tangible elaborado por sus propios compañeros/as y pueden ser usadas para un estudio posterior. En este apartado también se va preparando el denominado «cuento» entre todos los miembros del grupo.

Para preparar la transmisión de la información a través de la exposición oral (o narración teatral) es importante seguir una serie de pasos:

En primer lugar, se hace necesaria la elaboración de un guión que establezca los movimientos a seguir (desde la investigación previa o la recopilación de la información, hasta la creación de la infografía que sirve de complemento para la exposición o narración final de un «cuento» histórico). Además del guión, las infografías y las viñetas de cómic sirven de ayuda en la narración. Para ello es necesario que ese contenido se represente adecuadamente (mediante el uso de imágenes, gráficos, mapas, tablas, etc.). 
Como en el proceso anterior se ha extraído la información más relevante en un guión, en este segundo paso llega el momento de aprender y resumir los puntos más destacados de ese contenido (situando a cada uno en su correspondiente sección). En conclusión, a la hora de la narración teatralizada es importante ser organizados (y así saber cuándo y dónde intervenir en ella), por lo que el ensayo forma una parte trascendental en esta porción del proceso. Durante este ensayo previo es posible la práctica de aspectos útiles en una exposición (como los gestos, las pausas, la velocidad y la vocalización del orador). Además, durante la narración se permite el uso de vestimentas $\mathrm{u}$ objetos relacionados con el tema expuesto, ayudando al alumnado a situarse en un rol determinado.

Figura 7. Proceso de actividades y juegos durante el desarrollo del Proyecto.

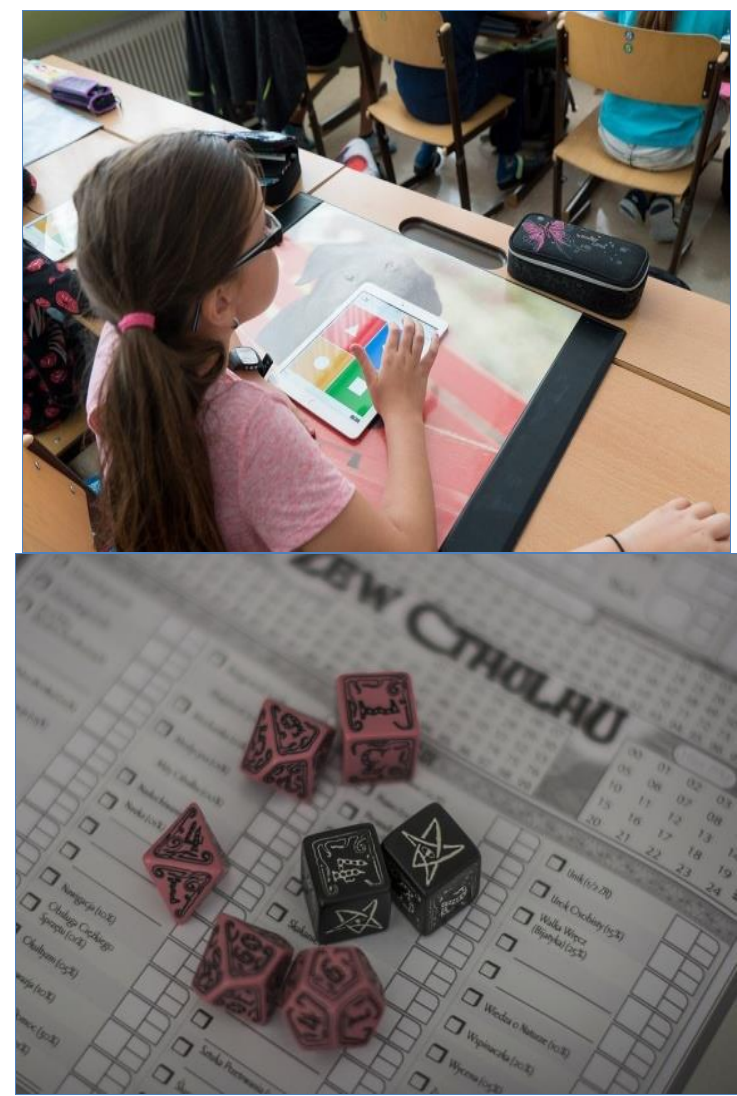

Fuente: Imagen superior izquierda de pixabay: actividades e investigación usando las nuevas tecnologías. Imagen superior derecha de pixabay: ejemplo de juego de rol.

En la última FASE C (cuyo procedimiento es grupal, narrativo, expositivo, comparativo y crítico), se lleva a cabo la presentación de los resultados obtenidos de dicha investigación mediante infografías y el «cuento» en grupo (por lo que cada miembro debe intervenir en él). En este estadio, el grupo tiene que crear una narración «teatral» que muestre cada uno de los pasos, en la que se desarrolle una historia basada en hechos reales e históricos. Esta narrativa se denomina «cuento», y tendrá que ser representado (no leído) por cada uno de los miembros del grupo, ante el resto de sus compañeros y compañeras. Es decir, realizar una exposición «teatral» mediante narrativa de los resultados obtenidos (desarrollando una o varias temáticas históricas) y con la base infográfica de fondo.

Finalmente, correspondiendo a la parte final de esta fase, y tras finalizar las exposiciones narrativas, se llevará a cabo la observación crítica y el análisis 
comparativo de las deducciones expuestas por cada grupo. El proceso final se realizará mediante una especie de mesa redonda, donde se expondrán los resultados globales y se compararán las conclusiones de los grupos con el mismo tema o el mismo episodio eruptivo.

\section{RESULTADO DEL MODELO}

Esta propuesta se puede desarrollar en varios cursos de la Educación Secundaria Obligatoria en España (y en contenidos de varios trimestres), aunque su adaptación también es posible en Bachillerato o en otros sistemas educativos. No obstante, la inclusión de esta estrategia en la educación secundaria (tanto en la ESO como en Bachillerato), forma parte de un proyecto de investigación e innovación en el aula que se pretende poner en funcionamiento próximamente por un grupo de jóvenes profesores recién salidos de sus respectivas carreras (en Geografía, Historia y Arte).

Por lo tanto, los resultados de esta propuesta educativa no han sido probados aún al tratarse de una propuesta meramente teórica, y con ello, cualquier mejora, sugerencia o inconveniente queda aparcado a un segundo proceso que servirá para establecer dificultades de implementación de la propuesta según el contexto del centro educativo, de las circunstancias de cada aula y de la necesidad de cada docente.

Como el objetivo de este trabajo no es desarrollar una programación con sus unidades didácticas, sino presentar un ejemplo de propuesta didáctica generalizada; la muestra de actividades, la organización, el tipo de juegos y la estructura final del trabajo, no serán expuestos en él (dejando este apartado incompleto y abierto a las necesidades y gustos de cada docente). 
Figura 8. Ejemplo de infografías para el desarrollo del Proyecto

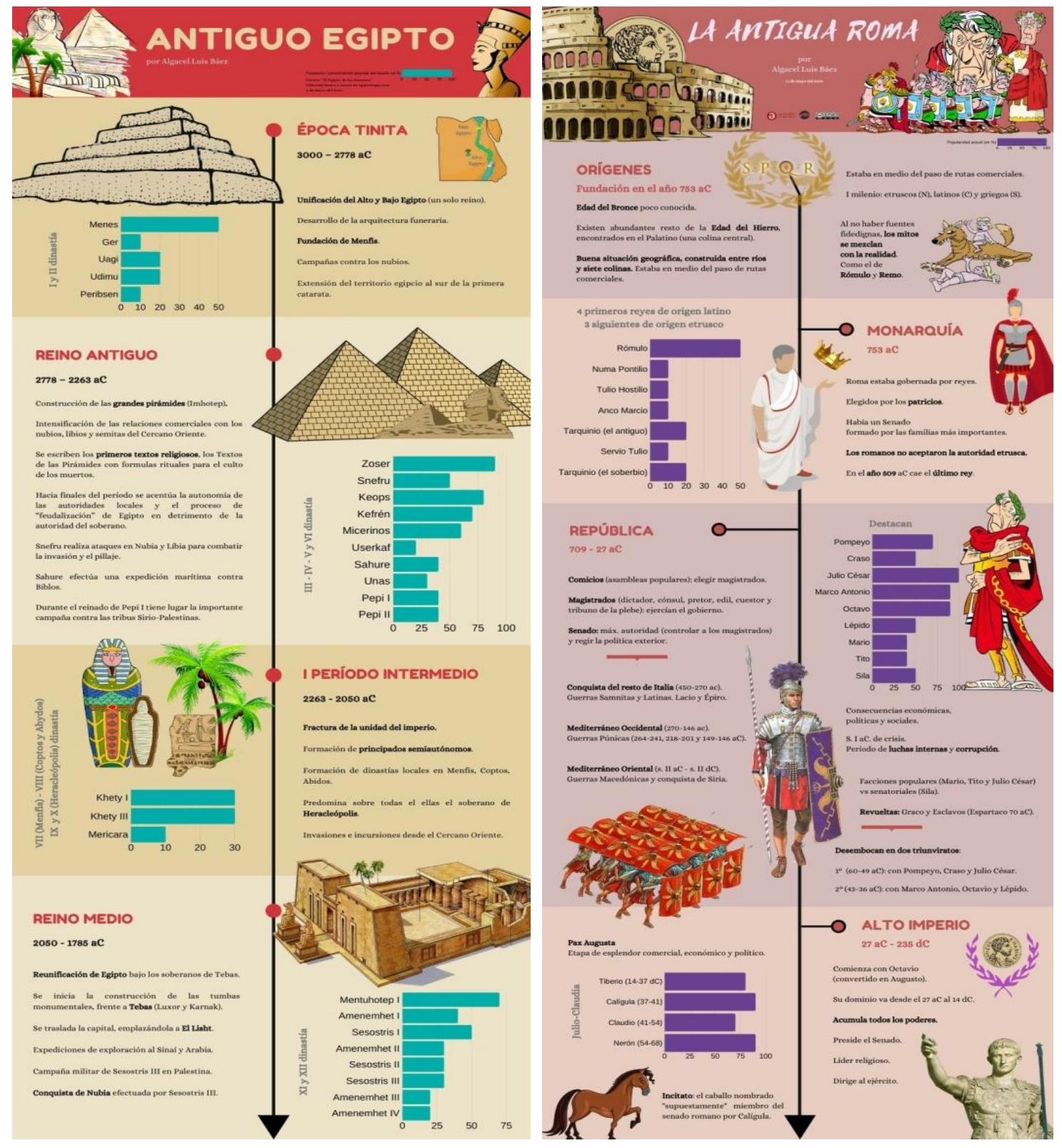

Fuente: Elaboración propia. Infografía del antiguo Egipto (imagen izquierda). Infografía de la antigua civilización romana (imagen derecha).

\section{CONCLUSIONES}

La Geografía y la Historia están presentes a diario en nuestras vidas, ya que casi cualquier tipo de actividad se ha visto determinada por su pasado o por algún aspecto de tipo geográfico. Su importancia queda resaltada en el currículo de la escuela secundaria, con la representación de materias y disciplinas directamente relacionadas, y con una presencia más que destacada de ellas. No obstante, no todo el tipo de contenido de estas materias tiene el mismo peso (este es el caso de las catástrofes naturales). Sin embargo, éstas constituyen una manifestación muy recurrente en la sociedad, alcanzando el estado de fenómeno geográfico, climático y geológico por excelencia. 
Así, el aprovechamiento didáctico de las grandes catástrofes naturales surge como alternativa a una educación confinada en una tradición obsoleta, y cada vez más en desuso, que se ha basado en contenidos memorísticos, metodologías anticuadas y poca utilidad social. En ese sentido, el uso didáctico de fenómenos poco presentes en la educación secundaria actual es resultado de la búsqueda de alternativas válidas para tal fin. El hecho de ser una investigación autónoma, grupal e individual, por medio de un Proyecto más amplio y común, genera inclusión, diversidad, motivación, auto-aprendizaje, colaboración y cooperación entre el alumnado, aspectos muy recurrentes en la educación del nuevo milenio.

Entre estos acontecimientos cabe destacar los aspectos geográficos que han influido de manera directa o indirecta en el devenir de cuestiones históricas y artísticas, de gran repercusión social, como son las grandes erupciones cataclísmicas que ha azotado a la humanidad. Los volcanes han resultado grandes destructores y creadores de paisajes, transformadores de civilizaciones y modificadores de conductas artísticas. Un estudiante puede comprender su entorno inmediato o un procedimiento científico, político o social, partiendo de hechos problemáticos del pasado relacionados con los volcanes con el objetivo de buscar soluciones actuales (crisis sociales, revueltas, situaciones políticas, transformaciones, cambios demográficos y climáticos).

Así, la utilidad de una estrategia didáctica se mide en el grado de implicación social, en su capacidad de adaptación o modificación y en el tipo de estrategia de aprendizaje del contenido (teniendo que ser significativa y motivacional). Partir del estudio de aspectos históricos, geográficos y artísticos, relacionados con grandes episodios volcánicos de la Historia, posee un alto grado social y una elevada practicidad, sobre todo, en disciplinas donde es cuestionada (como los casos de la Historia y, sobre todo, del Arte).

\section{BIBLIOGRAFÍA}

ALBEROLA ROMÁ, A. Un «mal año» en la España del siglo XVIII. Collection de la Casa de Velázquez, 2012, 131, 325-346.

ARAÑA, V. y ORTIZ, R. Riesgo Volcánico. En Martí, J. y Araña, V., La volcanología actual. Madrid: Consejo Superior de Investigaciones Científicas. Nuevas Tendencias, 1993, 578.

BÁEZ, W. Supererupciones: definición, mecanismos, productos e impacto. Asociación Española para la Enseñanza de las Ciencias de la Tierra, 2015, 23.1, 7379 .

CAMILLONI, I. Cambio climático. Facultad de Ciencias Exactas y Naturales, UBA, 2008, 18 (103), 39-45.

CANO SÁNCHEZ, J. Grandes erupciones volcánicas y su influencia en el clima. Agencia Estatal de Meteorología, 1994, 231-237. 
CUCHÍ, J. Posibles efectos de la erupción del Laki (Islandia) en 1783-1784 sobre el Alto Aragón. Instituto Lucas Mallada (Revista de Ciencias), 2015, 17, 159-175.

FERNÁNDEZ-FERNÁNDEZ, M.; VAQUERO, J.; GALLEGO, M. y ACERO, F. Impacto climático de las grandes erupciones volcánicas de 1783, 1808 y 1815 en el Suroeste de España. Proyecto Salvá-Sinobas, 2005, 2.

FERRADAS, P. La memoria es también por venir. Historia mundial de los desastres. Lima, Perú: Soluciones Prácticas, 2015.

FÚSTER CASAS, J. Volcanismo y cambio climático. Real Academia de las Ciencias, 2000, 115-129.

GARCÍA ALGUACIL, M. Cambios climáticos a lo largo de la historia de La Tierra. Propuesta didáctica para bachillerato. Centro de Estudios de Posgrados. Universidad de Jaén, 2019, 98.

GIL M. y YELA, M. La radiación difusa crepuscular en presencia de aerosoles estratosféricos: el impacto de la erupción del Monte Pinatubo. Óptica pura y aplicada, 1994, 27(1), 20-35.

MARTÍ, J.; HEYDRICH, M.; ROJAS, M. y HERNÁNDEZ, A. Aprendizaje basado en proyectos: una experiencia de innovación docente. REVISTA Universidad EAFIT, 2010, 46 (158), 11-21.

PÉREZ-FOLGADO, M. Cambios climáticos abruptos, o las consecuencias de traspasar umbrales. Enseñanza de las Ciencias de la Tierra, 2014, 207-216.

PÉREZ MOLINA, D.; PÉREZ MOLINA A. I. y SÁNCHEZ SERRA, R. El cuento como recurso educativo. (S. Área de Innovación y Desarrollo, Ed.) 3Ciencias. Revista de Investigación, 2013, 29.

PÉREZ TORRADO, F. J. Los peligros volcánicos en el aula (monográfico). Enseñanza de las Ciencias de la Tierra. ISSN edición impresa 1132-9157. Edición electrónica 2385-3484. 2015, vol. 23, 1, 3-4.

PROHOM, M. Incidencia de grandes erupciones volcánicas sobre la temperatura de la Península Ibérica (1856-1998). Grup de Climatologia. Parc Cientific de Barcelona. Universitat de Barcelona, 2001, 199-206.

PUJADAS, A.; BRUSI, D. y PEDRINACI, E. ¡Los volcanes han cambiado! Nuevos enfoques de terminología volcánica. Enseñanza de las Ciencias de la Tierra, 1999, 200-209.

REVERTE BERNABÉU, J. R. El Aprendizaje Basado en Proyectos como modelo docente. Experiencia interdisciplinar y herramientas Groupware. En Actas de las XIII Jornadas de Enseñanza Universitaria de la Informática (JENUI'07). Madrid: Thomson Paraninfo, Repositorio institucional de la Universidad de Alicante, 2007, 18. 
RISCH, R. y MELLER, H. Change and Continuity in Europe and the Mediterranean around 1600 BC. The Prehistoric Society, 2015, 81 (doi:10.1017/ppr.2015.10), 239264.

SÁNCHEZ, J. Qué dicen los estudios sobre el Aprendizaje Basado en Proyectos. Actualidad Pedagógica, 2013, 1-4.

SIGURDSSON, H.; CAREY, S. y ALEXANDRI, M. Marine Investigations of Greece's Santorini Volcanic Field. EOS, Transactions, American Geophysical Union., 2006, 87 (34), 337-348.

TARBUCK, E.; LUTGENS, F. y TASA, D. Ciencias de La Tierra. Una introducción a la Geología Física (8ª ed.). Madrid, España: Pearson Educación S. A., 2005, 710.

VERGARA, C. Volcán Tambora (Indonesia) en 1815: la erupción más grande de la historia y sus consecuencias. Geología. FCFM Universidad de Chile, 2014, 12.

\section{RECURSOS ELECTRÓNICOS}

CHUET-MISSÉ, J. P. (2020). Cómo dos erupciones volcánicas cambiaron la historia de la pintura. Disponible en: <https://www.cerodosbe.com/es/Viajer os/como-dos-erupciones-volcanicas-cambiaron-la-historia-delarte_20054220_102.html>. [Consulta: 28 de abril de 2020].

FLORES, O. (2017). El volcán que causó la Revolución Francesa. Disponible en: <https://bioteoria.wordpress.com/2017/06/17/el-volcan-que-causo-la-revolucionfrancesa>. [Consulta: 23 de abril de 2020].

GOETELEN, J. (2010). Islande, 1783: le Laki, volcan qui déclencha la Révolution française. Disponible en: <http://hommelibre.blog.

tdg.ch/archive/2010/04/17/islande-1783-le-laki-volcan-qui-declencha-la-revolutionfran.html>. [Consulta: 23 de abril de 2020].

LAMOUREUX, N. (2013). Les mystères de l'histoire - Le volcan de la Révolution. Disponible en: <https://www.lepoint.fr/culture/les-mysteres-de-l-

histoire-le-volcan-de-la-revolution-09-07-2013-1702139 3.php>. [Consulta: 23 de abril de 2020].

WEBER, G. (2007). Toba Volcano. Disponible en: <https://web. archive.org/web/20091228172553/http://www.andaman.org/BOOK/originals/WeberToba/textr.htm>. [Consulta: 23 de marzo de 2020]. 
(C) Copyright Algacel Luis Báez y Revista GeoGraphos, 2020. Este artículo se distribuye bajo una Licencia Creative Commons Reconocimiento-NoComercial 4.0 Internacional.

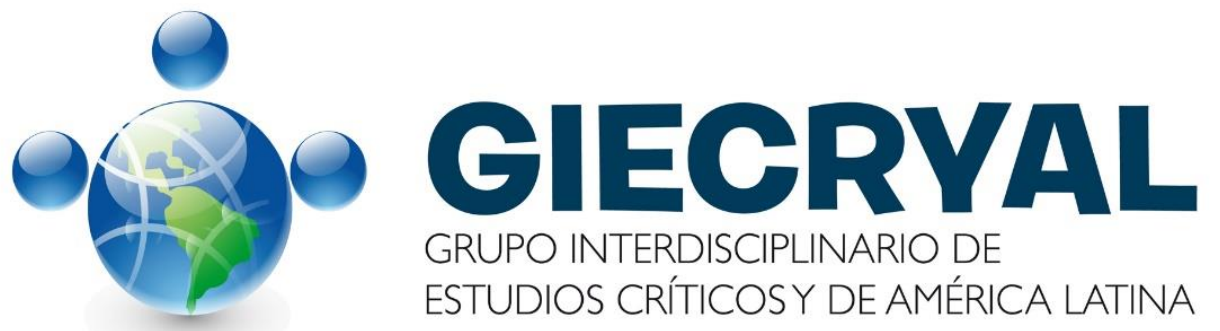

